International Journal of Current Advanced Research

ISSN: O: 2319-6475, ISSN: P: 2319 - 6505, Impact Factor: SJIF: 5.995

Available Online at www.journalijcar.org

Volume 6; Issue 5; May 2017; Page No. 3855-3859

DOI: http://dx.doi.org/10.24327/ijcar.2017.3859.0382

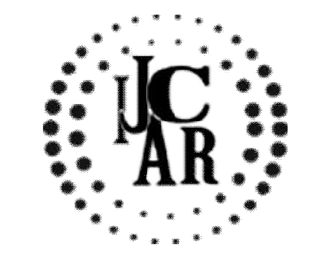

Research Article

\title{
COMPLICATIONS IN LAPAROSCOPIC CHOLECYSTECTOMY
}

\author{
Graziano Giorgio Maria Paul ${ }^{1}$ and Anthony Di Cataldo² \\ ${ }^{1}$ University of Catania Italy Dpt Sciences Medical of surgery and technologies advanted \\ ${ }^{2}$ University of Catania, Medical School Italy Dpt Sciences Medical of surgery and technologies advanted. \\ Adress via S Sofia 86 cap 95125 Catania Italy.
}

A R T I C L E I N F O
Article History:
Received $19^{\text {th }}$ February, 2017
Received in revised form $20^{\text {th }}$ March, 2017
Accepted $15^{\text {th }}$ April, 2017
Published online $28^{\text {th }}$ May, 2017

\section{Key words:}

Laparoscopic complications

of cholecystectomy

\begin{abstract}
A B S T R A C T
Indroduction: Laparoscopic gallbladder video surgery is considered the gold standard for cholecystectomy; But it has an ever-increasing number of iatrogenic lesions of the major biliary tract. Since in Italy they are about 100,000 a year, it is estimated that there are about 500 iatrogenic biliary lesions in the same period $(0.5 \%)$. This event occurs if the risk is to be ignored by analyzing the areas where the risk may occur during the clinical-care process. The purpose of this study is to study the complications most commonly occurring during or after laparoscopic cholecystectomy surgery is to identify the causes that determine the clinical risk and to propose prevention measures.

Materials and methods: From January 2006 to December 2016 at the Department of Science Surgical Specialist Medical II II of AOU Policlinico Catania 2016 were subjected to laparoscopic 3604 cholecystectomy interventions. In consultation with the business database and the operative directors of the period indicated our study, Showed that the complications found were in $\mathrm{n} 21(0.6 \%)$ patients. Results N 21 Conversions were performed, Bleeding $\mathrm{n} 2$, biliaren 1 collection, major biliary pathway lesions $\mathrm{n} 13$, intestinal lesions $n 4.15$ cases had a major biliary pathway injury; 6 of them were readily recognized at the operative site and solved by laparotomic reconversion: for 4 of them, the repair procedure provided a reconstruction on Kehr's T-tube, 2 to which a subsequent stent positioning was added; In the last case, he opted for the conversion as, without finding the common liver of liver, a liver-digiunostomy was performed on Y-Roux's lobe. Discussion: In our experience, it is noted that the variables that particularly affect the success of laparoscopic practice were: The operator's experience Being an operator at the beginning of a surgeon who in the phase immediately after learning training has performed interventions under 50 Other causes include inefficient instrumentation and the severity of the clinical case.

Conclusions: The risk factors identified in our study that are responsible for adverse events are related to general conditions (obesity, hepatopathy, cholecystitis) or surgical procedures (laparoscopic access) or. Failure to follow simple technical rules during cholecystectomy, or the absence of intraoperative cholangiography, which minimizes biliary risk
\end{abstract}

Copyright $₫ 2017$ Graziano Giorgio Maria Paul and Anthony Di Cataldo. This is an open access article distributed under the Creative Commons Attribution License, which permits unrestricted use, distribution, and reproduction in any medium, provided the original work is properly cited.

\section{INTRODUCTION}

Laparoscopic gallbladder video surgery is considered the gold standard for cholecystectomy; But presents an ever-increasing number of iatrogenic lesions of the major biliary pathway. These data, initially attributed to the novelty of the technique, tend to remain unchanged despite 25 years of the first VLC. It is calculated that the incidence is about one lesion every 200 VLC [1-2]. Since in Italy they carry about 100,000 a year, it is estimated that there are about 500 iatrogenic biliary lesions in the same period $(0.5 \%)$. The use of open method cholecystectomy is reserved for interventions considered to be

*Corresponding author: Graziano Giorgio Maria Paul University of Catania Italy Dpt Sciences Medical of surgery and technologies advanted difficult and / or complex, as in patients with flogic process leading to anatomical alteration of the biliary tree or in which adherence makes the laparoscopic approach more difficult; In the cancer of the gallbladder or in the bile ducts extraepathic. Clinical risk is understood as a probability that a patient is victim of an adverse event not due to the disease, but to medical care provided during the period of stay, resulting in a prolongation of the disease or a worsening of the health conditions [3]. Increasing the likelihood that such an event will occur will cause the risk to be ignored by analyzing the areas where the risk may occur during the clinical-care process. Knowing and reviewing folders, identifying and correcting the risk, monitoring the measures taken for prevention, are the first necessary interventions. (4.5) The purpose of the present study, through the study, is to analyze 
the complications most frequently occurring during or after laparoscopic cholecystectomy surgery to identify the causes of clinical risk and to propose prevention measures.

\section{MATERIALS AND METHODS}

From January 2006 to December 2016 at the Department of Science Surgical Specialist Medical II II of AOU Policlinico Catania 2016 were subjected to laparoscopic 3604 cholecystectomy interventions. In consultation with the business database and the operative directors of the period indicated our study, Noted the following: the complications found were $\mathrm{n} 21(0.6 \%)$ patients, of whom 15 cases had a major biliary pathway injury; 6 of them were readily recognized at the operative site and solved by laparotomic reconversion: for 4 of them, the repair procedure provided a reconstruction on Kehr's T-tube, 2 to which a subsequent stent positioning was added; In the last case, he opted for the conversion as, without finding the common liver of liver, a liver-digiunostomy was performed on Y-Roux's lobe. In another 2 cases, bleeding was the cause of the conversion. In our case, in a case presented a biliary collection complication. The bile was infected with the presence of a biliary peritonitis, which we remember being the most serious complication of a biliary lesion. In these cases, the best decision was to limit the peritoneal cavity, if possible through laparoscopic surgery, and to drain the bile duct externally. Prior to repair, a full biliary angiographic study was performed fig: 1

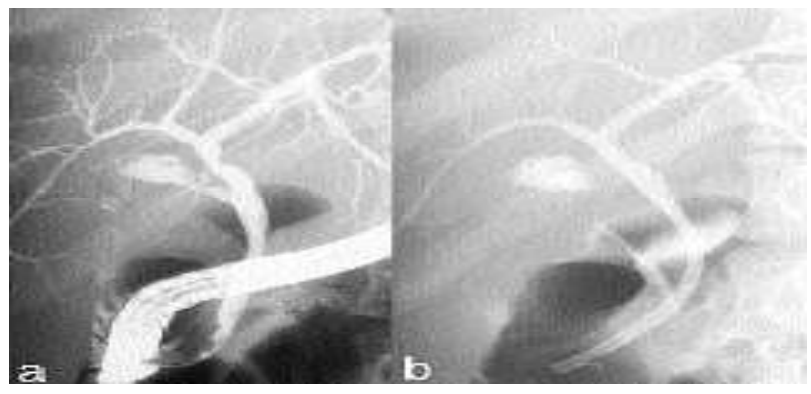

A) Contrast from the cystic duct.

B) Inserting a stent allows the fistula to be resolved

Determined the site and the extent and extent of biliary lesion and biliary digestion, was more effective in the complete sections of the primary biliary pathway and was carried out within and not more than 48 hours after the discovery of the lesion. Perforations of the loose joints that are readily recognized.

\section{RESULTS}

Table 1 Number of complications in laparoscopic cholecystectomy during 2006-2016.

\begin{tabular}{cc}
\hline Conversions & $\mathbf{2 1}$ \\
\hline Bleeding & 2 \\
Biliary-Collection & 1 \\
Major-biliary-pathways & 13 \\
Intestinal-injuries & 4 \\
\hline Total $21(0.6 \%)$ &
\end{tabular}

The bleeding was from the liver area where the gallbladder was located, and from abdominal wounds where laparoscopic instruments were inserted.
Table 2 Videolaparoscopic Risk Rates

\begin{tabular}{lc}
\hline \multicolumn{2}{c}{ Operator-,experience } \\
\hline - Beginner-Operator & $97 \%$ \\
- Average-Experience-Operator & $57 \%$ \\
- a-goodexperienced-operator & $0.60 \%$ \\
& Instrumentation \\
- sufficient & satus \\
- Goodordisposable & $0 \%$ \\
Clinical picture of the patient & $50 \%$ \\
- Symptomatic-spasms & \\
- Recurrent-biliary & $0 \%$ \\
- Complications of colitis (cholecystitis, empyema and jaundice) & $20 \%$ \\
\hline
\end{tabular}

Table 3 Adverse Events and Existing Complications in General Vascular Anesthesia:

\begin{tabular}{lr}
\hline Bleeding & \\
\hline Or within the abdomen & $10 \%$ \\
Or abdominal wall thickness on the path of laparoscopic & \\
instruments & $70 \%$ \\
Or injury to important blood vessels within the abdomen & $0 \%$ \\
Or from coagulatory or hematologic pathologies & $10 \%$ \\
Or by the use of anticoagulant or antiaggregating medicines & \\
for pre-existing & \\
cardiocirculation pathologies that increase the risk of & $10 \%$ \\
bleeding & \\
Gallbladder Injuries & $60 \%$ \\
- bile discharge from the liver and bile ducts & $20 \%$ \\
- coledoco residual calculus & $10 \%$ \\
- abdominal organs injury & $1 \%$ \\
- wound infections & $2 \%$ \\
- Acute pancreatitis & $3 \%$ \\
- major cardiocirculatory complications & $1 \%$ \\
- respiratory failure & $1 \%$ \\
- pneumonia acquired & $1 \%$ \\
- deep venous thrombosis & $1 \%$ \\
\hline
\end{tabular}

\section{DISCUSSION}

In our experience, it is noted that the variables that particularly affect the success of laparoscopic practice were: The experience of the operator Being considered an operator at the onset of a surgeon in the phase immediately following the learning training; A mid-life practitioner experiences a surgeon with a personal case of at least 60-70 complicated interventions; And finally a well-trained surgeon who carried out a number of personal interventions completed over 150 . $(4,5,6)$ The further variable is the status of the instrumentation. Which is called Mediocre: a multiinstrumentation where cutting edges do not expose their effectiveness within the first two approaches with the anatomical district to be dissected and the maintenance of the material is performed occasionally; Sufficient: If we consider the material with a minimum of half-yearly reviews, good : a disposable material (a term used to refer to all those materials and tools ready for use, stored in single sterilized and disposable packages). Another variable is the clinical picture of the patient. Which also evaluates the comorbidities at the time of diagnosis. We evaluate the presence of a asintomatic picture, subsequently a patient with recurrent colic, and patients with cholecystitis, empiemes or juices. An indicative risk index indicating the possibility of a safe laparoscopic approach occurs in the presence of a low incidence of complications in the presence of a well-experienced operator. With good instrumentation in asintomatic patients $(7,8,9$, 10). The risk index is in our opinion an important surgical training value because it requires a judgment of a real evaluation of the patient's comorbidity, suggesting the 
specialist the most appropriate method. Another important aspect is injury management, as the remoteness of repair depends on the first decisions taken when detecting the complication and the surgeon's experience in dealing with them; The definitive repair that can become more complex, the time of care can lengthen and thus increase the medicallegal implications $[11,12,13,14]$. Sometimes the initial picture of a iatrogenic lesion is exacerbated by the decision to remedy the operation of the laparoscopic procedure, which is indicated only for minor lesions. The conversion becomes obligatory in the following situations: 1 . Difficulty in finding the Calot triangle, or poor recognition of its elements (time of identification greater than 20 minutes from the beginning of the search); Uncontrollable bleeding; Abundant fluid biliary loss; 4. lesion of the anatomic structures close to the biliary biliary; In our study, lesion was recognized during videoparaphysia. With the decision to convert the intervention; To perform an immediate repair that was due to various factors such as: the conditions of the operating field, as a video -laparoscopic cholecystectomy, until then normal, had fewer problems. The surgeon's competence, which expired in (15.16.17.18); modification method which, in turn, depends on the type of injury. Partial lesions, where the continuity of the primary biliary tract is maintained, can be repaired with a suture stitch in detachable 4-0 or 5-0 absorbable material protected by a T-tube, whose long branch extends through A coledocotomy downstream of the lesion; Complete sections, especially if with loss of substance, need to be solved with hepatic-digiunostomy [19,20,21,22]; the use of imaging techniques by performing prior to Conversion of intraoperative cholangiography; The presence of a bleeding, the cause and the entity being assessed, since in severe bleeding conversion becomes necessary. Also in our study incorrect introduction and / or proper use of the trocar appears to be the major cause of bleeding ( 2 cases), an element that suggests a particular focus on their insertion and placement. An important aspect, then, consists of accurate information provided to the patient at the symptomatic level. Iatrogenic lesions that are not clinically manifest at intraoperative stage or 24 hours after postoperative hospitalization may be delayed for several days when presented in a symptomatic plane, the patient, if not previously informed, tends to underestimate these signals, considering them to be a normal posture Postoperative and thus delaying a surgical-surgical operation, greatly increasing the risk of morbidity and mortality. Therefore. In preoperative surgery, the patient's overall assessment was of primary importance in order to detect pathological processes that increase the risk of surgical complications, integrating the clinical picture with ultrasound and RNM. Data collected from anamnesis, objective examination, and image diagnostics have led the choice of intervention that involves the least possible risk for the patient., The fundamental choice is that of the operating technique, which was based on the ability and experience of the surgeon and related to the patient's pathological picture. The choice of the video laparoscopic method has determined the patient's accurate information on the possibility of an onscreen conversion, not as a mistake on the part of the practitioner, but as a choice to provide greater patient safety. $(23,24)$ During surgery, special attention has been paid to the control of the equipment for video-laparoscopic surgery; The ability to use disposable material equals the maximum efficiency value. By approaching the surgical procedure, particular attention has been paid to the introduction of air peritoneum and the insertion of trocar, since their incorrect positioning can also give rise to significant complications. Before starting the gallbladder dissection, it is fundamental to find the triangle Of Calot; If it is not located within 20 minutes, you opt for a conversion. Once the Calot triangle is delimited, the surgeon locates the cystic duct, the biliary and the vascular structures; In cases of anomalous presentation, the question arises whether to continue the operation in a videoaparoscopic method, or if an open reconversion is required. Same procedure for the detection of important adherence phenomena. In the case of misinformation, not seen by previous imaging examinations, the patient underwent intraoperative cholangiography in order to provide a clearer anatomical framework. In the case of possible operative complications, reconversion necessarily presents a higher chance of successful intervention than a laparoscopic approach; The surgeon's decision came from A careful assessment that included the degree of injury, the state of the operating field, the technical-instrumental repair option, the general clinical condition of the patient, and, above all, a sincere analysis of their technical capabilities $(25,26,27,28)$. Another important aspect is the monitoring and management of the post-operative course, it is Drainage if placed. The positioning of the drainage level at the liver lobe if we decide the attachment was maintained for 24-48 hours, in our experience so we can also report the minimum leakage within that timed window, optimal for a better repair result in case Of complications. Depending on the extent of the leak loss from bile duct drainage. There can be a history of biliary lesions occurring with different clinical manifestations in relation to the degree of bile duct stenosis and the presence or absence of peritoneal biliary collections. Only one-third of them occur intraoperatively (as a major biliary duct injury for the cystic duct), while two-thirds of them occur in the postoperative period; The accompanying clinical picture becomes fundamental because it is closely related to the type of lesion; The clinical signs are jaundice and They were peritoneal. Ultrasound and especially the RM cholangi are usually sufficient for proper diagnosis of such lesions $[29,30,31,32]$. Endoscopic therapy plays a key role in the treatment of biliary pathways surgical lesions and represents the second phase of a diagnostic-therapeutic procedure. However not dilated, it is best to implant the prosthesis without prior sphincterotomy, so as to preserve the integrity of the Oddi sphincter. Even in the case of spreading from the bed of the gallbladder, when the sphincterotomy is contraindicated or not indicated, a short prosthesis that holds the papilla has the same hydrodynamic effect of papillotomy. The implantation of a prosthesis without sphincterotomy is simple and has no particular problems (37, 38, 39 40). Obviously, in the case of a thorax, formed because no subhepatic drainage has been left, this will have to be drained per percutaneous echo or TC-guided. Major biliary fistula If discovered during surgery, lateral lesions of common bile duct go Treated in the same course with a bilio-biliary or bilio-digestive anastomosis.

Very often, however, recognition occurs in the immediate post-operative. In this case endoscopic stenting treatment can lead to fistula healing in $70-80 \%$ of cases $(41,42,43,44)$. 


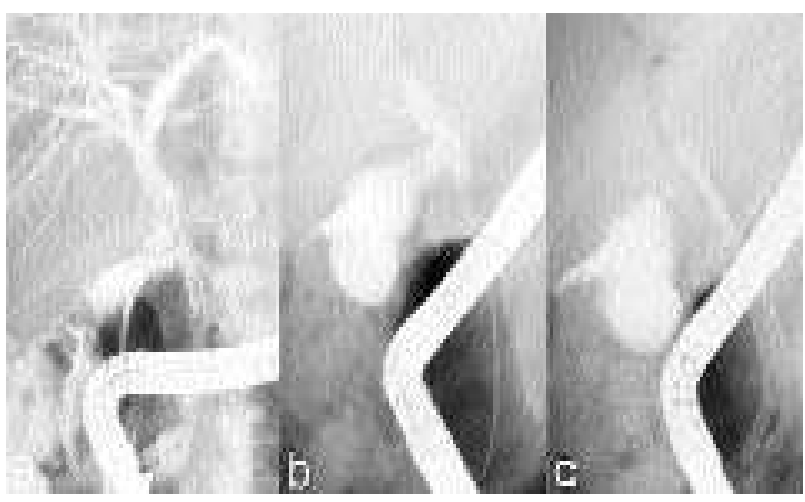

A b c visualization of biliary lesion and site

Preventing the development of stenosis Isolated stenosis the traditional treatment of biliary tract stenosis is surgical, with the reconstruction by liver-digiunostomy on Roux-en-Y. And surgery is usually proposed only in endoscopy failures $(45,46,47,48)$ the complete sections of the biliary ducts. These are lesions that generally require surgical repair. Therefore, if it is acknowledged during surgery it is imperative that a biliodigestive derivation or bilio-biliary anastomosis is performed. They are recognized early in the post-ope-Rationale In selected cases, it is possible to perform a prosthesis treatment by means of transapillary percutaneous endoscopic rendezvous. $(49,50,51,52)$ These are very sophisticated techniques that require a great deal of experience and manuality and are therefore performed only in a few centers of endoscopy $(53,54$,

\section{CONCLUSIONS}

The risk factors identified in our study that are responsible for adverse events are related to general conditions (obesity, hepatopathy, cholecystitis) or surgical procedures (laparoscopic access) or. Failure to comply with simple technical rules during cholecystectomy or the absence of intraoperative cholangiography to minimize biliary risk Conversion of laparoscopic technique to conventional laparotomy technique should not be considered a complication but a safety Patient, as when the surgeon feels he or she wants to undertake open surgery to dominate a critical or unclear situation from anatomical or pathological point of view, this evaluation will get the goal of resolving the lesion by early detection of the lesion or pathology With a therapeutic approach to surgical injuries. The risk index is, in our opinion, an important surgical training value because it requires a judgment of a patient's assessment, suggesting the specialist the most appropriate method, with the reduction of the latter being related to a number of factors illustrated Indicating the necessary corrective procedures for therapeutic success.

\section{References}

1. Fletcher DR, Hobbs MS, Tan P et al. Complications of cholecystectomy: risks of the laparoscopic approach and protective effects of operative cholangiography: a population-based study. Ann Surg 1999; 229:449-457.

2. De Reuver PR, Rauws EA, Bruno MJ et al. Survival in bile duct injury patients after laparoscopic cholecystectomy: a multidisciplinary approach of gastroenterologists, radiologists, and surgeons. Surgery 2007;142:1-9
3. Ministero della Salute, Documento della Commissione Tecnica sul Rischio Clinico (DM 5 marzo 2003). Risk management in Sanità, il problema degli errori, Roma, 2004.

4. Nuzzo G, Giuliante F, Murazio M et al. Complicanze biliari della colecistectomia: la gestione della fase acuta delle lesioni iatrogene della via biliare principale. $O s p$ Ital Chir 2008; 14:126-136.

5. Olsen D. Bile duct injuries during laparoscopic cholecystectomy. Surg Endosc 1997; 11:133-138.

6. Amboldi M, Amboldi A, Bonandrini $\mathrm{L}$ et al. Complications of videolaparoscopic cholecystectomy: a retrospective analysis of 1037 consecutive cases. Int Surg 2011; 96(1):35-44.

7. Khan MH, Howard TJ, Fogel EL et al. Frequency of biliary complications after laparoscopic cholecystectomy detected by ERCP: experience at a large tertiary referral center. Gastrointest Endosc 2007; 65:247-252.

8. Bonandrini L, Caputo $\mathrm{P}$, Faccini $\mathrm{M}$ et al. Le complicanze biliari in corso di colecistectomia videolaparoscopica, riflessioni sulla metodica e sulle indicazioni nella fase di apprendimento. Minerva Chir 2001; 56:85-91.

9. Stewart L, Way LW. Bile duct injuries during laparoscopic cholecystectomy. Factors that influence the results of treatment. Arch Surg 1995; 130: 11231129.

10. Nuzzo G, Giuliante F, Ardito F. Complications of laparoscopic cholecystectomy. In: Biliary lithiasis. Basic Science, Current Diagnosis and Management. Springer-Verlag, Torino, IT, 2008.

11. Nuzzo G. Le lesioni iatrogene della via biliare principale. Collana Monografica della Società Italiana di Chirurgia, N.

12. Relazione biennale al $104^{\circ}$ Congresso. Roma, Società Italiana di Chirurgia, 2002.

13. Schmidt SC, Settmacher U, Langrehr JM et al. Management and outcome of patients with combined bile duct and hepatic arterial injuries after laparoscopic cholecystectomy. Surgery 2004; 135: 613-618.

14. Lillemoe KD. Current management of bile duct injury. Br J Surg 2008; 95:403-405.

15. Khan MH, Howard TJ, Fogel EL et al. Frequency of biliary complications after laparoscopic cholecystectomy detected by ERCP: experience at a large tertiary referral center. Gastrointest Endosc 2007; 65:247-252.

16. Codice di deontologia medica, Titolo III - Rapporti con il cittadino; Capo II - Doveri del medico e diritti del cittadino, Art 24. Capo IV, Art 30, 31, 32, 33, 34, 35 .

17. Deziel DJ, Millikan KW, et al. Complications of laparoscopic cholecystectomy: A national survey of 4,292 hospitals and an analysis of 77,604 cases. Am J Surg 1992;165:L9-14

18. MACFADYEN BV JR, VECCHIO R, RICARDO AE. Bile duct injury after laparoscopic cholecystectomy. The United States experience. Surg Endosc 1998; 12:315-21

19. GRAZIANO A (2007). lesioni biliari in corso di colecistectomia laparoscopica. OSPEDALI D'ITALIA, vol. 2, p. 190-200, ISSN: 0030-6258 
20. Paolo Graziano GM, Cavallaro M, Graziano A (2016) the Familial Adenomatous Polyposis. A Difficult Problem, Between Prevention and Treatment. J Surg Surgical Res 2(1): 005-009.

21. Cavallaro A, Paolo Graziano GM, Cavallaro M, Graziano A (2015) the Neuroendocrine Cancer. Personal Comments and Operational Remarks. J Surg Surgical Res 1(3): 053-058. DOI: 10.17352/24542968.000014

22. Cavallaro M, Paolo Graziano GM, Cavallaro A, Graziano A (2015) The Stent Evolution in Colo-Rectal Emergencies. J Surg Surgical Res 1(3): 045-048.

23. Giorgio $\mathrm{mp}$ graziano n., Antonio di cataldo $\mathrm{n}$ and Antonino graziano., Lithiasis In Urinary Diversions or Post Prostatectomy. Int J Recent Sci Res. 8(4), pp. 16357-16363. (2017)

24. GiorgioMP Graziano, Anthony Graziano and Anthony Di Cataldo.2017, What The Anti-Reflux Surgery Ideal?. Int J Recent Sci Res. 8(1), pp. 15106-15110. (2017)

25. Bismuth $\mathrm{H}$, Lazorthes F. Les traumatismes operatoires de lavoie biliare principale. J Chir (Paris) 1981; 118:601-9

26. Bergman JJGHM, VAN DEN BRINK GR, et al. Treatment of bile duct lesions after laparoscopic cholecystectomy. Gut 1996;38:141-7

27. Strasberg Sm, Hertl M, Soper NJ. An analysis of the problem of biliary injury during laparoscopic cholecystectomy. J Ann Coll Surg 1995;180:101-125

28. Neuhaus P, Schmidt SC et al. Classification and treatment of bile duct injuries after laparoscopic cholecystectomy. Chirurg 2000;71:166-73

29. Bismuth H, Majno PE. Biliary strictures: classification based on the principles of surgical treatment. World $J$ Surg 2001;25(10):1241-4

30. Roberts Rh, Pettigrew Ra, Van Rij AM. Bile leakage after laparoscopic cholecystectomy: biliary anatomy revisited. Aust NZ J Surg 1994;64:254-257

31. Davidoff AM, Pappas TN, et al. Mechanism of major biliary injury during laparoscopic cholecystectomy. Ann Surg 1992;215:196-202

32. NORTHOVER JMA, TERBLANCHE J. A new look at the arterial supply of the bile duct in man and its surgical implications. Br J Surg 1979;66:379-84

33. Hugh TB. New strategies to prevent laparoscopic bile duct injury - surgeons can learn from pilots. Surgery 2002; 132(5):826-35.

34. Huibregtse K, Katon RM, Tytgat GNJ. Endoscopic treatment of postoperative biliary strictures. Endoscopy 1986; $18: 133-7$

35. Pitt HA, Miyamoto T, Parapatis SK, ET AL. Factors influencing outcome in patients with postoperative biliary strictures. Am J Surg 1982;144:14-21

36. Martin DF. Endoscopic retrograde cholangiopancreatography should no longer be used as a diagnostic test: an independent verdict. Digest Liver Dis 2002;34(5):381-2

37. Giorgio Maria Paolo Graziano, et al On Traumatic Lesions of The Pancreas World Journal of Research and Review (WJRR) ISSN:2455-3956, Volume-2, Issue-6, June 2016 Pages 24-28
38. Graziano Giorgio Maria Paolo, et al Which Therapeutic Treatment in Gastric Lymphoma World Journal of Research and Review (WJRR) ISSN:24553956, Volume-2, Issue-6, June 2016 Pages 06-09

39. Giorgio Maria Paolo Graziano1, et al A Descriptive Study of Differentially Placed Hydatid cysts International Multispecialty Journal of Health (IMJH) ISSN: [2395-6291] [Vol-2, Issue-5, May- 2016]

40. Giorgio Maria Paolo Graziano, et al Which Treatment for Abdominal Trauma in Pediatric Age. International Journal of New Technology and Research (IJNTR) ISSN:2454-4116, Volume-2, Issue-6, June 2016 Pages 2428

41. 40) Giorgio Maria Paul Graziano et al Early Epithelial Ovarian Carcinoma Treatment. International Journal of New Technology and Research (IJNTR) ISSN:2454-4116, Volume-2, Issue-5, May 2016 Pages 69-74

42. Khalid TR, Casillas VJ, Montalvo BM, Centeno R, Levi JU. Using MR cholangiopancreatography to evaluate iatrogenic bile duct injury. AJR 2001;177:1347-52

43. Bjorkman Dj, Carr-Loc et al. Postsurgical bile leaks: endoscopic obliteration of the transpapillary pressure gradient is enough. Am J Gastroenterol 1995;90:2128-33

44. Chow S, Bosco Jj, et al. Successful treatment of postcholecystectomy bile leaks using nasobiliary tube drainage and sphincterotomy. Am $J$ Gastroenterol 1997;92:1839-43,

45. Giorgio Maria Paolo Graziano et al Clinical and Molecular Anatomy of Gastrointestinal Stromal Tumors (GIST) International Journal of New Technology and Research (IJNTR) ISSN:2454-4116,

46. Giorgio Maria Paul Grazianol et al Vascular Thoracic Fibrous Adipose Tissue (New Disease) J Pharm Biomed Sci $\mid$ Vol. 06 No. 07 | 419-424

47. Paul Graziano GM, Santo C, Luigi S, et al (2016) One Time Surgery in Contemporary Diseases of the Abdominal Wall and Pelvis in the Elderly. $J$ Surg Surgical Res 2(1): 018-020.

48. Giorgio Maria Paul Graziano1 Which Treatment In Cystic Tumors Of The Pancreas: Conservative Or Resection. International Journal of Current Advanced Research Vol 5, Issue 8, pp 1190-1198, August 2016

49. Giorgio Maria Paul Graziano1 Diagnostic And Therapeutic In The Intestinal Duplication International Journal of Recent Scientific Research Vol. 7, Issue, 8, pp. 13000-13003, August, 2016

50. Graziano Giorgio Maria Paolo, et al. Humanization of Care Ethical and Social in Clinical-Care World Journal of Research and Review Volume-3, Issue-6, December 2016 Pages 01-08

51. Sugiyama M, Mori T, Atomi Y. Endoscopic nasobiliary drainage for treating bile leak after laparoscopic cholecystectomy. Hepato gastroenterology 1999;46:762-5

52. Raute M, Podlech $\mathrm{P}$, et al. Management of bile duct injuries and strictures following cholecystectomy. World $J$ Surg 1993; 17:553-62

53. Foutch PG, Harlan JR, Hoefer M. Endoscopic therapy for patients with a postoperative bile leak. Gastrointest Endosc 1993;39:416-21

54. Marks JM, Ponsky JL, et al. Biliary stenting is more effective than sphincterotomy in the resolution of biliary leaks. Surg Endosc 1998;12:327-30

55. Ponchon T, Gallez JF, et al. Endoscopic treatment of biliary tract fistulas. Gastrointest Endosc 1989;35:490-8 